\title{
"Late" manifestations of cardiovascular syphilis occurring in a young man
}

\author{
A P BROWN, K D DAWKINS, D J PARKER \\ From the Regional Cardiothoracic Unit, St George's Hospital, London
}

SUMMARY A young man who presented with a short history of angina was found to have syphilitic coronary ostial stenosis six years after the primary infection. He was successfully treated with bilateral internal mammary grafts.

Syphilis became a rare disease in the West after the widespread use of penicillin in the 1950s. The present incidence in the United Kingdom has fallen to less than 4000 new cases per annum. ${ }^{1}$ The late manifestations of the disease are now so rare that they are generally considered to be medical curiosities, although occasional cases are seen in elderly patients who contracted the infection before penicillin became generally available.

\section{Case report}

A 25 year old farmer presented with a three week history of chest pain typical of angina occurring on moderate exertion. He had previously been very fit and active. He smoked 10 cigarettes daily and occasional cannabis. He gave no history of genital ulceration or venereal infection and he denied any homosexual relationships. The most likely source of infection was thought to have been a casual contact six years previously while he was on holiday in India. There was a positive family history of ischaemic heart disease: his father had undergone coronary artery bypass grafting at the age of 54 years and his grandfather had sustained a myocardial infarct in his $50 \mathrm{~s}$.

On examination there were no features of congenital syphilis or stigmata of hyperlipidaemia. Blood pressure was $110 / 60 \mathrm{~mm} \mathrm{Hg}$, and heart sounds were normal with no murmurs. Detailed neurological examination showed no abnormality. Full blood count, urea, electrolytes, liver function tests, and a fasting lipid profile were all normal. The erythrocyte sedimentation rate was $10 \mathrm{~mm}$ in one

Requests for reprints to Dr K D Dawkins, Wessex Cardiothoracic Centre, Southampton General Hospital, Southampton SO9 4XY. hour. A rapid plasma reagin card test for syphilis was positive at a low titre of $1: 8$ and the Treponema pallidum haemagglutinating antibody and FTA(ABS) tests were also positive. The cerebrospinal fluid contained $0.4 \mathrm{gs} /$ litre of protein and serology was negative.

The resting electrocardiogram and chest radiograph were normal. During a formal treadmill exercise test the haemodynamic response was normal but the patient developed chest pain during stage five of the standard Bruce protocol. The pain was associated with $4 \mathrm{~mm}$ horizontal ST segment depression.

At cardiac catheterisation the pressures were all normal. Aortography showed minor irregularity of a normal sized aortic root. There was no aortic regurgitation. A tight left coronary ostial stenosis (fig la) prevented engagement of an $8 \mathrm{~F}$ catheter, and a moderate stenosis of the right coronary ostium just allowed entry of the catheter. Introduction of the catheter into either ostium resulted in an immediate fall in pressure with "ventricularisation" of the pressure trace. Aortic sinus injections confirmed the presence of bilateral ostial stenosis and the administration of nitrates did not alter the appearances. The distal coronary vessels were normal.

At operation the ascending aorta was found to be thickened and inflamed. There was a sharp line of demarcation with apparently normal aorta $1 \mathrm{~cm}$ above the supra-aortic ridge. The aortic valve cusps were entirely normal. Neither coronary ostium permitted the introduction of a $1 \mathrm{~mm}$ probe. The right internal mammary artery was grafted to the distal right coronary artery, the left internal mammary artery to the left anterior descending artery, and a saphenous vein graft to the left circumflex artery.

A biopsy specimen of the aortic wall showed severe aortitis with focal destruction of the media and fragmentation of the internal elastic laminae. 
Fig 1 Coronary arteriograms (a) showing left coronary ostial stenosis (left anterior oblique view) and (b) four months after operation showing enlargement of the left coronary ostium.

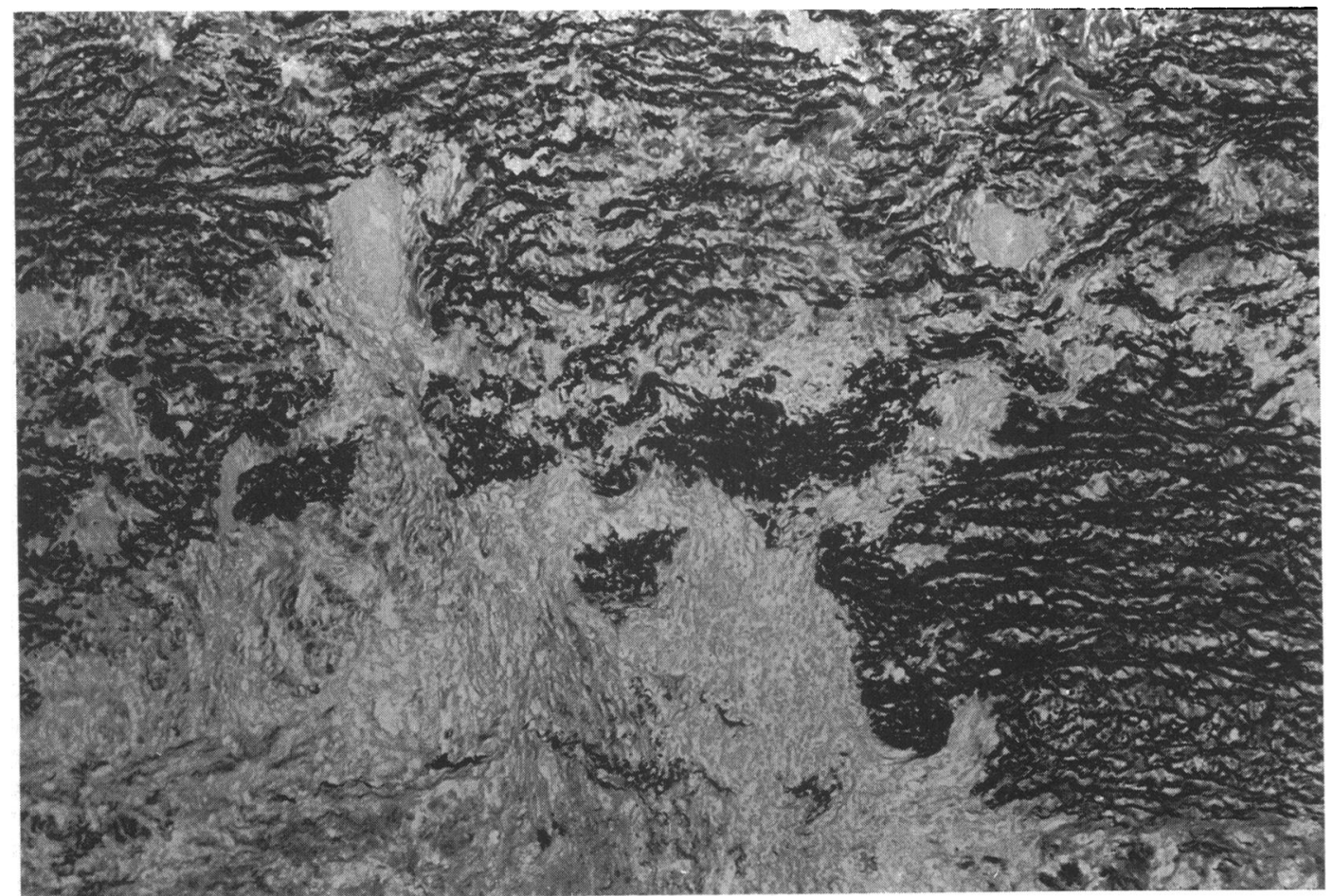

Fig 2 Photomicrograph of biopsy specimen of the ascending aorta showing vasculitis, focal destruction of the media, and fragmentation of the elastic lamina associated with a florid inflammatory cell response. (Elastic-van Gieson, original magnification $\times 100$.) 
There was a florid chronic inflammatory infiltrate with plasma cells around the vasa vasorum and within the adventitia (fig 2).

Postoperative recovery was uneventful. The patient was treated with prednisolone $10 \mathrm{mg}$ twice daily for five days and procaine penicillin $1.8 \mathrm{mU}$ intramuscularly daily for 21 days.

Subsequently he resumed normal activities and a follow up exercise test was normal. He underwent elective repeat catheterisation four months after operation. Aortography was normal. Both coronary ostia permitted engagement of an $8 \mathrm{~F}$ catheter with ease (fig $1 \mathrm{~b}$ ) and all three coronary grafts were patent.

\section{Discussion}

Syphilis affects the cardiovascular system in several ways. ${ }^{2}$ An aortitis is seen most frequently; this can lead to root dilatation, aneurysm formation, aortic regurgitation, and stenosis of the coronary ostia. Pathologically there is an endarteritis of the vasa vasorum associated with a mesoaortitis, patchy loss of elastic tissue, and fibrous replacement. Exceptionally rare manifestations of cardiovascular syphilis include myocardial gumma and coronary arteritis. Cardiac involvement is more common in men, ${ }^{3}$ and there is also a reported association with systemic hypertension. ${ }^{4}$

Isolated coronary ostial stenosis is seen most frequently in association with atheromatous disease. It is found in approximately $0.1 \%$ of all patients investigated with coronary artery disease. ${ }^{5}$ Necropsy data suggest that coronary ostial stenosis occurs in $20-30 \%$ of cases of cardiovascular syphilis. ${ }^{67}$ Scharfman and colleagues noted a low incidence of myocardial infarction and suggested that this was due to the slow progression of the disease. ${ }^{6}$ In contrast, Heggtveit reported a series of 100 cases of syphilitic aortitis ${ }^{7} ; 26$ of these cases had coronary ostial stenosis, which was associated with aortic regurgitation in 14. There were 24 cases of myocardial infarction; four were caused by ostial stenosis and three by a combination of ostial stenosis and atheroma. Syphilis was thought to have been the primary cause of death in 33 cases, and sudden death occurred in five patients with coronary ostial stenosis.

Surgical treatment is aimed at increasing myocardial perfusion, either by some form of reconstructive procedure on the coronary ostium, ${ }^{8-10}$ or alternatively by coronary artery bypass grafting. Dubost et al introduced endarterectomy for syphilitic coronary ostial stenosis in $1959 .^{8}$ The procedure was technically difficult, especially if the ostium was not visible from the aorta, and a consid- erable proportion of patients developed restenosis during long term follow up. ${ }^{11}$ More recently, saphenous vein bypass grafts have been used in several centres, ${ }^{12-15}$ but the superior long term patency of the internal mammary artery ${ }^{16}$ may make this the conduit of choice.

We treated our patient with prednisolone as well as penicillin in an attempt to avoid the JarischHerxheimer reaction. Sudden death is said to occur in this syndrome, possibly due to acute swelling of the aortic wall and occlusion of the coronary ostia. For this reason, antibiotic treatment was delayed until myocardial revascularisation had been undertaken.

The overall incidence of syphilis is falling slowly in the United Kingdom, and the proportion of patients presenting with late manifestations of the disease (currently one third) is rising. ${ }^{1}$ In recent years most of these cases have been in patients in middle and old age. For example, in a series from Denmark between 1960 and 1970105 patients presented with late syphilis of whom 92 were over the age of 45 years. ${ }^{17}$ Forty patients had cardiovascular syphilis and six also had neurological involvement.

There will now be very few patients who contracted the disease before the antibiotic era, and so we should expect to see a higher proportion of younger patients in whom the early infection was not treated. Possible reasons for missing early syphilis include an asymptomatic infection, infection masked by antibiotics given for another reason (for example, gonorrhoea), and a low index of suspicion now that the disease is uncommon.

The latent period between exposure and late disease may be as short as three to five years and presentation in patients in their 20 s is not unknown. ${ }^{14}$ Syphilis has protean manifestations and mimicks many other diseases; it should not be forgotten as a cause of angina especially in a young patient.

We thank Dr E A F Davidson, Department of Genitourinary medicine for helpful advice.

\section{References}

1 Extract from the Annual Report of the Chief Medical Officer (1982). Br J Vener Dis 1984;60:199-203.

2 Silver MD. Cardiovascular pathology. Vol 2. New York: Churchill Livingstone 1983:707-37.

3 Clark EG, Danbolt $M$. The Oslo study of the natural course of untreated syphilis: an epidemiologic investigation based on a restudy of the BoeckBruusgaard material. Med Clin N Am 1964; 48:613-23.

4 Rockwell DH, Yobs AR, Moore MB. The Tuskegee 
study of untreated syphilis: the thirtieth year of observation. Arch Intern Med 1964;114:792-8.

5 Hutter JA, Pasaoglu I, Williams BT. The incidence and management of coronary ostial stenosis. $J$ Cardiovasc Surg (Torino) 1985;26:581-4.

6 Scharfman WB, Wallach JB, Angrist A. Myocardial infarction due to syphilitic coronary ostial stenosis. $\mathrm{Am}$ Heart $J$ 1950;40:603-13.

7 Heggtveit HA. Syphilitic aortitis: a clinicopathologic autopsy study of 100 cases, 1950 to 1960 . Circulation 1964;29:346-55.

8 Dubost C, Blondeau P, Piwnica A, et al. Syphilitic coronary obstruction: correction under artificial heartlung and profound hypothermia at $10^{\circ} \mathrm{C}$. Surgery 1960;48:540-7.

9 Connolly JE, Eldridge FL, Calvin JW, Stemmer EA. Proximal coronary artery obstruction: its aetiology and treatment by transaortic endarterectomy. $N$ Engl J Med 1964;271:213-9.

10 Beck W, Barnard CN, Schrire V. Syphilitic obstruction of coronary ostia successfully treated by endarterectomy. Br Heart $J$ 1965;27:911-5.

11 D'Allaines C, Lacour-Gayet F, Blondeau P, et al. Re- sultats a distance des coronarites ostiales operees. Arch Mal Coeur 1979;72:1173-9.

12 Michaud P, Chassignolle J, Age C, Champsaur G. Coronarite ostiale syphilitique: a propos de onze cas traites chirurgicalement. Ann Chir 1980;34:210-5.

13 Hirano M, Hawasuji M, Tsuchiya K, Watanabe Y, Fukatani G, Iwa G. Surgical treatment of syphilitic aortic insufficiency associated with stenosis of both coronary ostia. Kyobu Geka 1980;33:794-7.

14 Moraes CR, Oliveira PS, Rodrigues JV, Escobar M. Revascularizacao miocardica na estenose sifilitica da arteria coronaria esquerdo: relato de caso. Arq Bras Cardiol 1984;42:285-7.

15 Przybojewski JZ, Van Rensburg CJ. Syphilitic coronary ostial stenosis. $S$ Afr Med J 1983;64:407-12.

16 Loop FD, Lytle BW, Cosgrove DM, et al. Influence of the internal-mammary-artery graft on 10 year survival and other cardiac events. $N$ Engl J Med 1986;314:1-6.

17 Fischer A, Kristensen K, Husfelt V. Tertiary syphilis in Denmark 1961-1970: a description of 105 cases not previously diagnosed or specifically treated. Acta Derm 1976;56:485-8. 